\title{
In vitro studies of the stimulation of insulin secretion and B-cell proliferation by rat placental lactogen-II during pregnancy in rats
}

\author{
M. Kawai and K. Kishi \\ New Drug Research Laboratories, Shionogi \& Co., Ltd, Futaba-cho 3-1-1. Toyonaka, \\ Osaka 561, Japan
}

\begin{abstract}
The present study investigated the effect of rat placental lactogen-II (rPL-II) on insulin secretion and B-cell proliferation of the maternal islets during the last half of pregnancy in rats using a homologous system. Pancreatic islets were isolated from nonpregnant rats and rats at day 13 of pregnancy and cultured for 8 days in medium containing trophoblast culture medium or purified hormones. The medium was changed daily and insulin concentrations were determined by measuring immunoreactivity. The number of proliferating $B$ cells were determined by double staining for both insulin and $5^{\prime}$-bromo- $2^{\prime}$-deoxyuridine (BrdU) incorporated into replicating DNA during the last $24 \mathrm{~h}$ of incubation. rPL-II-enriched medium, in which trophoblasts of placentae from rats at day 13 of pregnancy were incubated for 8 days, was added to the islet culture system. Insulin concentration in the medium of non-pregnant rat islets was significantly increased and doubled on incubation in $100 \%$ trophoblast culture medium. Addition of purified rPL-II to the culture medium of pregnant rat islets stimulated insulin secretion at the concentrations of $50-500 \mathrm{ng} \mathrm{ml}^{-1}$ in a dose-dependent manner. The stimulatory effect of $\mathrm{PPL}-\mathrm{II}$ on insulin secretion was found to be more than double that with rat prolactin (rPRL) and rat growth hormone (rGH) at $100 \mathrm{ng}$ $\mathrm{ml}^{-1}$. For determination of B-cell proliferation, non-pregnant rat islets were incubated with

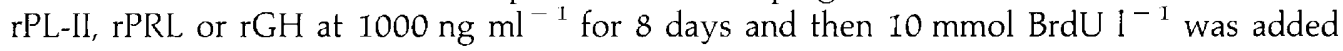
during the last $24 \mathrm{~h}$ of incubation. rPL-II $(5.30 \pm 0.36 \%)$, rPRL $(3.79 \pm 0.34 \%)$ and $\mathrm{rGH}$ $(2.87 \pm 0.29 \%)$ significantly increased the rate of incorporation of BrdU into the B cells compared with that of the control $(1.34 \pm 0.18 \%)$. These results indicate that rPL-II directly regulates insulin secretion and B-cell proliferation of maternal islets during the last half of pregnancy in rats.
\end{abstract}

\section{Introduction}

The glucose demands of the fetus increase markedly with fetal growth, especially during the last half of pregnancy (Metcalfe et al., 1994). The maternal pancreatic islets are thought to adapt to this increased demand for glucose by increasing their insulin secretory response and by B-cell proliferation (Green and Taylor, 1972; Parsons et al, 1992). Previous studies have indicated that, in comparison with somatogenic hormones, lactogenic hormones secreted during pregnancy are more potent stimulators for inducing functional and structural changes of pancreatic B cells (Sorenson and Parsons, 1985; Brelje and Sorenson, 1991; Parsons et al., 1992). Although the biological activities of the prolactin-growth hormone families, such as placental lactogen (PL), prolactin (PRL) and growth hormone $(\mathrm{GH})$, on B-cell function have been widely studied (Nielsen 1982; Nielsen et al., 1986; Brelje et al., 1989), much of the work has been carried out with heterologous rather than homologous systems. However, human growth hormone is known to have somatogenic and lactogenic activities when used with rat tissues (Nicoll et al., 1986). Since it is possible that

Received 8 July 1996. other members of the prolactin-growth hormone family behave in a similar manner, data obtained from experiments using homologous systems are important for analysing the precise effects of these hormones on their own tissues.

In rodents, two placental lactogens, PL-I, PL-II, have been identified, one is present at mid-pregnancy (PL-I) and the other during the last half of pregnancy (PL-II). PL-I and PL-II are known to possess structural similarity with prolactin rather than $\mathrm{GH}$, and thus, are lactogenic rather than somatogenic hormones in rodents (Nicoll et al., 1986).

Brelje et al. (1993) reported that rat PL-I (rPL-I) and mouse PL-I and PL-II (mPL-I, mPL-II) have the potential to enhance islet function by increasing the insulin secretory response and proliferation of $B$ cells in a homologous system. However, no information is available on the role of $\mathrm{rPL}-\mathrm{II}$ in pancreatic islet function in rats, even though the maximum concentration of rPL-II in maternal circulation in rats is approximately $1000 \mathrm{ng}$ $\mathrm{ml}^{-1}$ (Ogren and Talamantes, 1988; Kishi et al., 1991). Moreover, during the last half of pregnancy, when the glucose demands of the fetus increase markedly, rPL-I disappears from maternal circulation and rPL-II is secreted predominantly as a lactogenic hormone into the maternal circulation. 
The present study was undertaken to investigate the effect of rPL-II on insulin secretion from and B-cell proliferation into the maternal islets during the last half of pregnancy in rats using a homologous system.

\section{Materials and Methods}

\section{Animals}

Female Sprague-Dawley rats weighing $250-350 \mathrm{~g}$ were housed under controlled lighting ( $12 \mathrm{~h}$ light: $12 \mathrm{~h}$ dark, lights on 08:00 h) and temperature $\left(23 \pm 1^{\circ} \mathrm{C}\right)$ conditions with free access to food and water.

\section{Isolation and culture of islets}

Pancreatic islets were isolated from adult rats as described by Gotoh et al. (1987) with several modifications. Animals were anaesthetized with Nembutal $\left(50 \mathrm{mg} \mathrm{kg}^{-\mathrm{I}}\right.$ ). A polyethylene tube (outer diameter $1 \mathrm{~mm}$ ) was inserted into the common bile duct, and the distal end of the duct was clamped. Approximately $15 \mathrm{ml}$ of ice-cold Hank's balanced salt solution (HBSS, $\mathrm{pH} 7.4$ ) with $0.3 \mathrm{mg}$ collagenase $\mathrm{ml}^{-1}$ (type XI, Sigma, St Louis, MO) and $2 \%(w / v)$ BSA (Sigma) was injected. The distended pancreas was carefully excised to prevent it from bursting and placed into a $50 \mathrm{ml}$ plastic conical tube. After incubation of the distended pancreas for $35 \mathrm{~min}$ in a water bath $\left(37^{\circ} \mathrm{C}\right)$ without shaking, ice-cold HBSS was added to stop the digestion. The sample was then centrifuged ( $350 \mathrm{~g}$ for $5 \mathrm{~min}$ ), the supernatant was discarded and $15 \mathrm{ml}$ of ice-cold HBSS was added. After the digested tissue was agitated several times with a pipette, the plastic tube was centrifuged at $160 \mathrm{~g}$ for $2 \mathrm{~min}$ and the supernatant was discarded. The digested tissue was poured into a $15 \mathrm{ml}$ centrifuge tube containing $3 \mathrm{ml} 27 \%(\mathrm{w} / \mathrm{v})$ Ficoll 400 (Pharmacia Biotech AB, Uppsala) solution and vortexed for $2-3 \mathrm{~s}$. The tissue suspension was overlaid on a discontinuous Ficoll gradient $(20.5$ and $11 \%, 4$ and $2 \mathrm{ml}$, respectively) followed by centrifugation at $450 \mathrm{~g}$ for $15 \mathrm{~min}$. The islets at the $20.5 / 11 \%$ interface were collected with a Pasteur pipette in RPMI-1640 culture medium $(10 \mathrm{mmol}$ glucose $1^{-1}$, Gibco, Grand Island, NY) which was supplemented by $10 \mathrm{mmol}$ Hepes $\mathrm{l}^{-1}, 23.8 \mathrm{mmol} \mathrm{NaHCO}_{3} \mathrm{l}^{-1}, 5 \%$ fetal bovine serum (FBS), $50 \mathrm{mg}$ gentamicin $\mathrm{ml}^{-1}, 50 \mathrm{U}$ penicililin $\mathrm{ml}^{-1}, 50 \mathrm{mg}$ streptomycin $\mathrm{ml}^{-1}, \mathrm{pH} \mathrm{7.4}$. Groups of 25 islets were transferred to 24 -well plates and incubated at $37^{\circ} \mathrm{C}$ under $95 \%$ air: $5 \% \mathrm{CO}_{2}$ for up to 8 days. The medium was changed every day and stored at $-20^{\circ} \mathrm{C}$ until assayed. The insulin concentration in the culture medium was assayed using a kit (Shionoria Insulin Kit, Shionogi \& Co., Ltd, Osaka).

\section{Culture of trophoblast cells}

Culture of trophoblast cells was performed as described by Kishi et al. (1993). Briefly, conceptuses were collected from pregnant rats at day 13 of pregnancy. The fetus and decidua basalis were discarded and the basal zone and the labyrinth were collected. The tissue was finely minced and minced tissue was dispersed with dissociation medium containing $0.1 \%(\mathrm{w} / \mathrm{v})$ collagenase and $0.002 \%(w / v)$ DNase. The cell suspension was centrifuged at $700 \mathrm{~g}$ for $5 \mathrm{~min}$, resuspended in $2 \mathrm{ml}$ of dissociation medium and centrifuged at $700 \mathrm{~g}$ for $15 \mathrm{~min}$ through a $40 \%(\mathrm{v} / \mathrm{v})$ Percoll density gradient. Cells banded at a density of about $1.049 \mathrm{~g} \mathrm{ml}^{-1}$ were collected. These cells contained at least three types of trophoblast cells: giant cells with a single nucleus or multinuclei, round cells and small round trophoblast cells. An immunohistochemical study had previously confirmed that approximately $70 \%$ of the trophoblast cells obtained by the above procedure are positive for rPL-II (Kishi et al., 1993). The cells obtained from the placentae were resuspended at

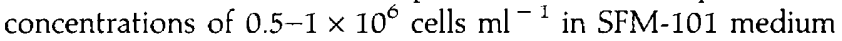
(10 mmol glucose $1^{-1}$, insulin free; Nissui, Tokyo) supplemented with $26 \mathrm{mmol} \mathrm{NaHCO}_{3} \mathrm{l}^{-1}, 10 \mathrm{mmol}$ Hepes $\mathrm{I}^{-1}$, $50 \mathrm{mg}$ gentamicin $\mathrm{ml}^{-1}, 50 \mathrm{U}^{-1}$ penicillin $\mathrm{ml}^{-1}$ and $50 \mathrm{mg}$ streptomycin $\mathrm{ml}^{-1}, \mathrm{pH}$ 7.4. Cells were incubated at $37^{\circ} \mathrm{C}$ under $95 \%$ air: $5 \% \mathrm{CO}_{2}$ for up to 6 days. The medium was changed every day and stored as a pool at $-20^{\circ} \mathrm{C}$ until assayed.

\section{Hormones}

rPL-II was purified from the placentae of rats at day 19 of pregnancy as described by Kishi et al. (1992). The homogeneity of purified rPL-II was monitored with SDS-gel electrophoresis. Purified rPL-II was characterized by a major band of molecular mass of $24.5 \mathrm{kDa}$ and a minor band of a molecular mass of $25.0 \mathrm{kDa}$ under reducing conditions (data not shown). Rat prolactin (NIADDK-rat PRL-B-5) and rat growth hormone (NIADDK-rat GH-B-8) were supplied by NIADDK.

\section{BrdU and insulin immunocytochemistry}

The number of proliferating $B$ cells was determined by staining for both insulin and $5^{\prime}$-bromo-2'-deoxyuridine (BrdU) incorporated into the replicating DNA. After 7 days of culture in the presence of the hormone, the islets were incubated with $\mathrm{BrdU}$ at a final concentration of $10 \mathrm{mmol} \mathrm{l}^{-1}$ for the last $24 \mathrm{~h}$ of incubation in the presence of hormone. When the incubation was finished, the islets were washed with $\mathrm{HBSS}\left(\mathrm{Mg}^{2+}\right.$, $\mathrm{Ca}^{2+}$-free: HBSS-F) and digested with $0.1 \%$ trypsin (Difco, Detroit, $\mathrm{MI}), 0.1 \%(\mathrm{w} / \mathrm{v}) \mathrm{BSA}$ in HBSS-F for $6-7 \mathrm{~min}$ in a shaking water bath at $37^{\circ} \mathrm{C}$. Cold HBSS-F was added to stop the digestion and the separated islet cells were fixed with $70 \%$ aqueous ethanol for $30 \mathrm{~min}$ at room temperature. The fixed cells were placed on poly-L-lysine-coated glass slides and allowed to air-dry for a few seconds. The islet cells attached to

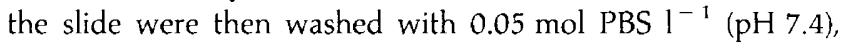

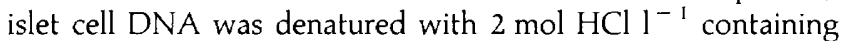
$0.5 \%(\mathrm{v} / \mathrm{v})$ Triton $\mathrm{X}-100$ for $1 \mathrm{~h}$ at room temperature. After washing several times with PBS, the islet cells were incubated with 10\% normal goat serum (Chemicon Inc., Temecula, CA) in PBS with $0.1 \%$ Triton $X-100$ for $2 \mathrm{~h}$ at room temperature. All of the following procedures were carried out at $4^{\circ} \mathrm{C}$. After washing several times with PBS, the islet cells were incubated with a monoclonal mouse anti-BrdU antibody (Chemicon Inc.) for $24 \mathrm{~h}$ on a rotating table. The islet cells were washed several times with PBS and were immunostained for BrdU with 1:200 dilution of Rhodamine-conjugated goat anti-mouse immuno- 
globulin G (Biosource, Camarillo, CA) in PBS/Triton X for $24 \mathrm{~h}$ on a rotating table. After washing several times with PBS, the islet cells were incubated with a diluted polyclonal guinea-pig anti-insulin antibody (ZYMED Lab. Inc., San Francisco, CA) for $24 \mathrm{~h}$ on a rotating table and washed several times with PBS. The islet cells were immunostained for insulin with 1:100 dilution of fluorescein isothiocyanate (FITC)-conjugated goat anti-guinea-pig immunoglobulin G (Biomeda Corp., CA) in $\mathrm{PBS} /$ Triton $\mathrm{X}$ for $24 \mathrm{~h}$ on a rotating table. The islet cells were washed several times with PBS and mounted with glycerol-PBS (glycerol:PBS; 7:3) solution.

\section{Measurement of proliferation rate of $B$ cells}

The number of $B$ cells incorporating BrdU into their nuclei was determined by direct observation with a Nikon Optiphot microscope equipped for epifluorescence (Nikon Corp., Tokyo). Areas were chosen at random from one side of the slide to the other side. The percentage of B cells with BrdU-labelled nuclei was determined by counting at least 500-1000 FITC-stained $B$ cells for each slide.

\section{Statistical analyses}

All the data were expressed as means \pm SEM. Initially, the data from three or more groups were analysed for homogeneity of variance with Bartlett's test. Data meeting this criterion were analysed by one-way analysis of variance and subsequently by Tukey's test. Data showing heterogeneity of variance were analysed initially by the Kruskal-Wallis test and then by Tukey's test. Differences with $P<0.05$ were considered significant.

\section{Results}

Differences in insulin secretion between islets from nonpregnant and pregnant rats

Islets from nonpregnant rats and rats at days 13 and 17 of pregnancy were incubated for $2 \mathrm{~h}$ in RPMI-1640 at glucose concentrations of $2.5-10 \mathrm{mmol} \mathrm{l}^{-1}$. Glucose stimulated insulin secretion in the islets of non-pregnant and pregnant rats in a dose-dependent manner (Fig. 1). The secretion of insulin from the islets of rats at day 17 of pregnancy was the greatest, and that from islets of pregnant rats was usually greater than that from the islets of non-pregnant rats.

\section{Effects of trophoblast-culture medium on insulin secretion} from islets

Trophoblasts were isolated from the placentae of rats at day 13 of pregnancy and incubated in SFM-101 for 6 days. Islets from nonpregnant rats were incubated for 8 days in SFM containing 0 (control), 10,50 or $100 \%$ of trophoblast-cultured medium and $5 \%$ FBS. Trophoblast-culture medium stimulated insulin secretion in a dose-dependent manner (Fig. 2). SFM-101 containing 50 or $100 \%$ of trophoblast-culture medium significantly increased insulin secretion compared with that of the

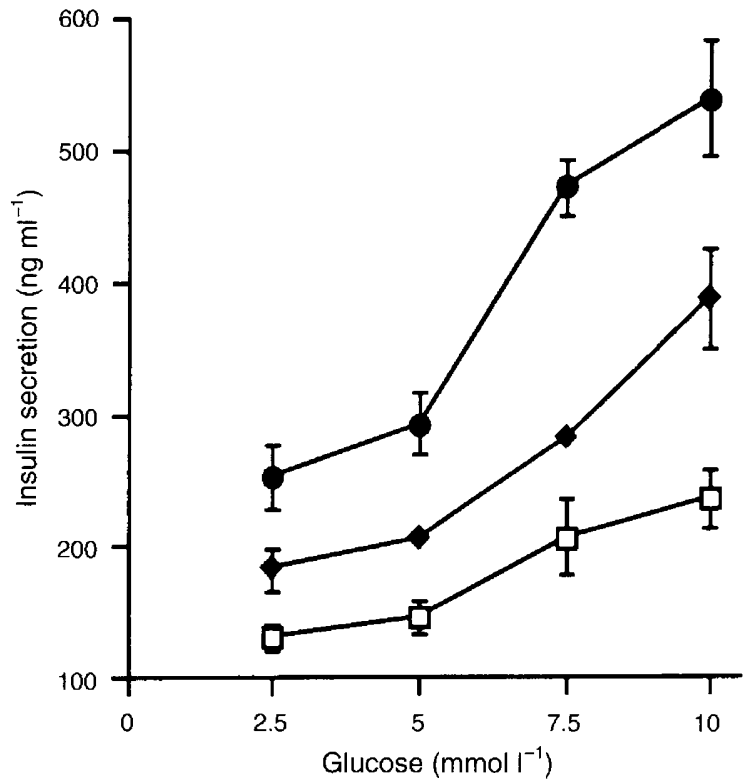

Fig. 1. Effects of pregnancy on insulin secretion at glucose concentrations of $2,5-10 \mathrm{mmol}^{-1}$. The islets, obtained from non-pregnant $(\square)$, day $13(\bullet)$ or day $17(\bullet)$ pregnant rats, were incubated for $2 \mathrm{~h}$ in RPMI-1640 at each glucose concentration. In the islets from rats at day 17 of pregnancy, glucose significantly stimulated insulin secretion at concentrations from 2.5 to $10 \mathrm{mmol} \mathrm{I}^{-1}$ compared with nonpregnant rats $(P<0.01, n=4)$. In the islets from rats at day 13 of pregnancy, glucose significantly stimulated insulin secretion at 5 and $10 \mathrm{mmol} \mathrm{I}^{-1}$ compared with non-pregnant rats $(P<0.05, n=4)$.

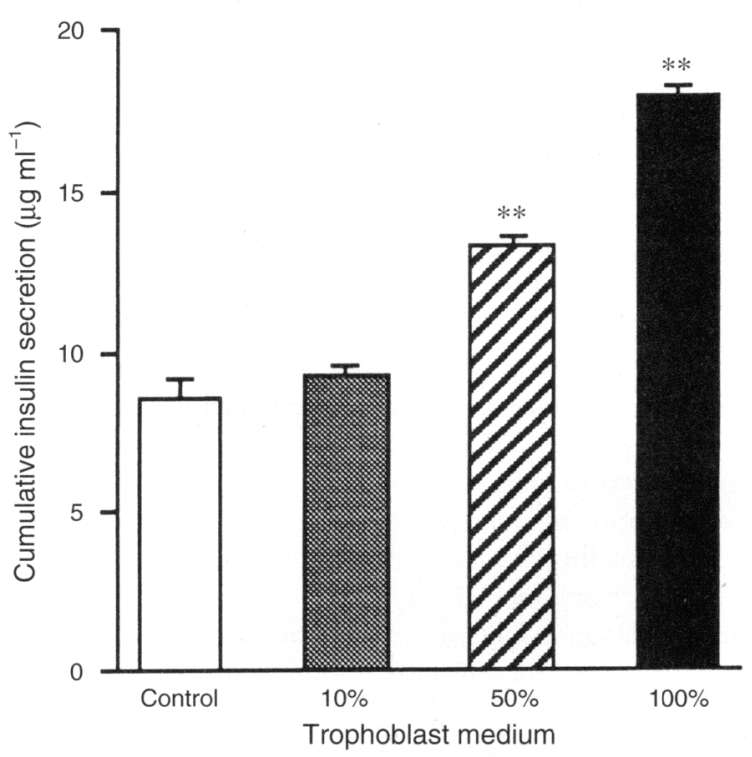

Fig. 2. Effects of rat trophoblast-culture medium on insulin secretion by non-pregnant rat islets. The non-pregnant rat islets were incubated for 8 days in SFM-101 containing 0 (control), 10,50 or $100 \%$ of trophoblast-culture medium. $* * P<0.01$ compared with control. Values are expressed per well, and each bar represents mean \pm SEM $(n=4)$.

control medium $(P<0.01)$, and $100 \%$ trophoblast-cultured medium doubled insulin secretion by the islets of nonpregnant rats in comparison with the control medium. 

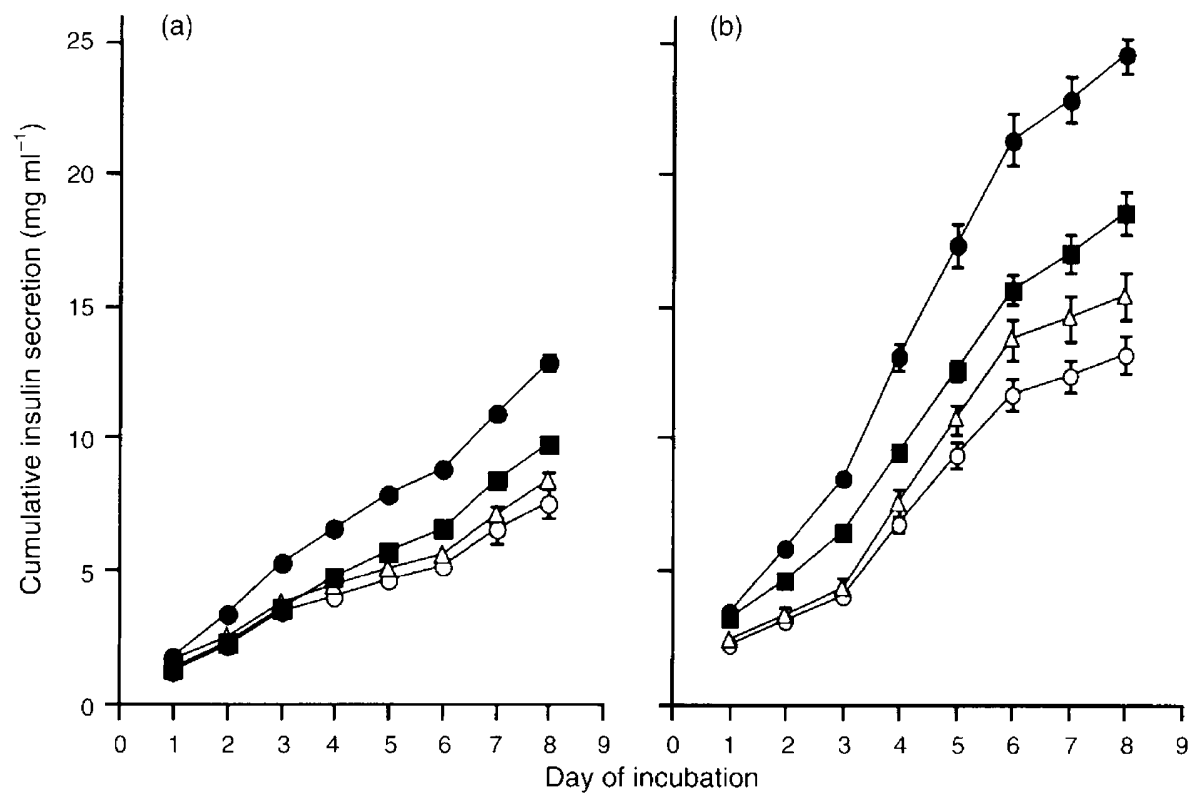

Fig. 3. Effects of $(-)$ rat placental lactogen-II (rPL-II), ( $)$ rat prolactin (rPRL) or $(\triangle)$ rat growth hormone $(\mathrm{rGH})\left(1000 \mathrm{ng} \mathrm{ml}^{-1}\right)$ on insulin secretion by islets from (a) non-pregnant rat and (b) rat at day 13 of pregnancy; (O) control. The given values represent the cumulative insulin secretion up to 8 days. In the islets from non-pregnant rats, rPL-II and rPRL significantly stimulated insulin secretion compared with the control on each day and after day 5 of incubation, respectively $(P<0.01 ; n=4)$. In the islets from rats at day 13 of pregnancy, both rPL-II and rPRL significantly stimulated insulin secretion on each day of the experiment $(P<0.01 ; n=4)$.

Effects of rPL-II, prolactin and growth hormone on insulin secretion from islets

The islets of non-pregnant rats and rats at day 13 of pregnancy were incubated for 8 days in the presence of $1000 \mathrm{ng} \mathrm{ml}^{-1} \mathrm{rPL}-\mathrm{II}, \mathrm{rPRL}$ or $\mathrm{rGH}$. The insulin concentrations in the culture medium were assayed by radioimmunoassy and the data were expressed daily as a cumulative value. In the experiment using islets from nonpregnant rats, rPL-II significantly stimulated insulin secretion throughout the experiment when compared with the control; when compared with prolactin, there was a significant difference in effects from day 2 of incubation $(P<0.01)$ (Fig. 3). Prolactin significantly stimulated insulin secretion only after day 5 of incubation $(P<0.01)$. Growth hormone tended to cause an increase in insulin secretion, but the effect was not significant. In the experiment using islets from rats at day 13 of pregnancy, rPL-Il had a greater effect on insulin secretion than did prolactin, although both hormones significantly stimulated insulin secretion throughout the experiment $(P<0.01)$ (Fig. 3). Growth hormone tended to increase insulin secretion, but again the effect was not significant. The overall pattern of insulin secretion was characterized by a higher magnitude of secretory responses in pregnant rat islets than in those of non-pregnant rats. The dose-response effects of rPL-II on insulin secretion were examined in islets from rats at day 13 of pregnancy. rPL-II stimulated insulin secretion at $50-500 \mathrm{ng} \mathrm{ml}^{-1}$ in a dosedependent manner with the effect reaching a plateau at $500 \mathrm{ng}$ $\mathrm{ml}^{-1}$ (Fig. 4). The stimulatory effect of rPL-II on insulin secretion was more than double that with rPRL and rGH at the concentration of $100 \mathrm{ng} \mathrm{ml}^{-1}$.

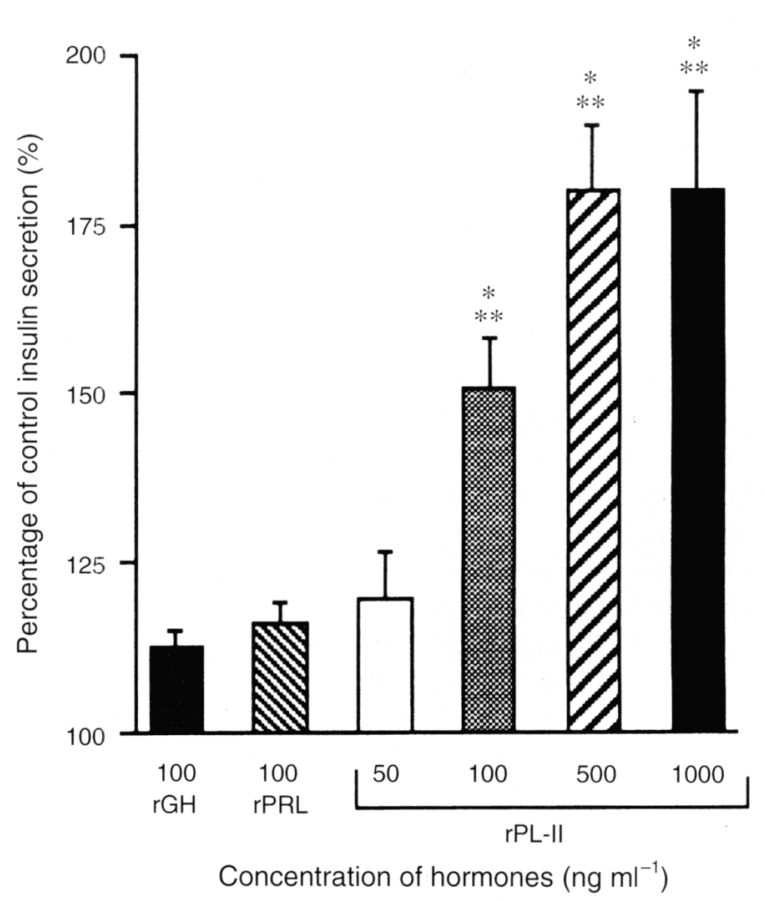

Fig. 4. Dose-response effects of rat placental lactogen-II (rPL-II) on insulin secretion by islets from rats at day 13 of pregnancy. The islets were cultured with the indicated concentrations of hormones for 8 days. Data were cumulated to day 8 of incubation and values are expressed per well as the percentage of the control. rPL-II stimulated insulin secretion in a dose-dependent manner. ${ }^{*} P<0.01$ compared with rat growth hormone $(\mathrm{rGH}) .{ }^{*} p<0.01$ compared with rat prolactin (rPRL). Each bar represents mean $\pm \operatorname{sEM}(n=4)$. 

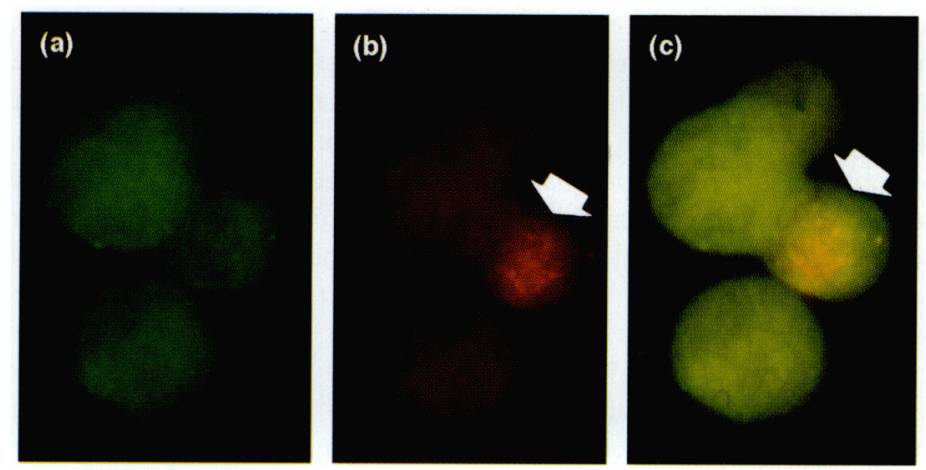

Fig. 5. Double staining tor $B$ cells of cultured adult rat islets with $10 \mathrm{mmol}$ $5^{\prime}$-bromo-2'-deoxy-uridine (BrdU) $]^{-1}$ present for the final $24 \mathrm{~h}$ of culture. (a) rat B cells immunostained for insulin (green); (b) rat B cells immunostained for BrdU (red); (c) double-staining picture for the B cells immunostained for BrdU (orange) and insulin (light green). The arrows indicate nuclei with incorporated BrdU. Magnification: $\times 890$.

\section{BrdU and insulin immunocytochemistry}

The evaluation of proliferating B cells was performed by double-staining for both insulin and BrdU incorporated into replicating DNA. When the $B$ cells were identified using an excitation filter of $450-490 \mathrm{~nm}$, B cells were immunostained as a whole cell body with bright green fluorescence (insulinpositive) (Fig. 5a). However, when the BrdU-incorporated cells were identified using an excitation filter of $510-560 \mathrm{~nm}$, the nuclei with BrdU were immunostained as red fluorescence (BrdU-positive) (Fig. 5b). By using the above two filters, the double-staining picture of both BrdU (orange) and insulin (light green) could be photographed (Fig. 5c). When the anti-BrdU antibody or the anti-insulin antibody was replaced with normal goat serum, no staining was observed in any cells.

\section{Effects of $r P L-I I, r P R L$, and $r G H$ on B-cell proliferation}

The effects of rPL-II, rPRL, and rGH on B-cell proliferation was examined by culturing non-pregnant rat islets with rPL-II, $\mathrm{rPRL}$ or $\mathrm{rGH}$ at $1000 \mathrm{ng} \mathrm{ml}^{-1}$ for 8 days including the last $24 \mathrm{~h}$ of incubation with $10 \mathrm{mmol} \mathrm{BrdU} 1^{-1}$. The rate of proliferation of $B$ cells was expressed as the percentage of the $B$ cells incorporating BrdU of the total B cells counted. rPL-II, rPRL and rGH significantly increased the rate of incorporation of $\mathrm{BrdU}$ into the $\mathrm{B}$ cells compared with that of the control and their rates were $5.30 \pm 0.36 \%, 3.79 \pm 0.34 \%$ and $2.87 \pm 0.29 \%$, respectively (Fig. 6). The control had a rate of $1.34 \pm 0.18 \%$. The increase in rate induced by rPL-II was found to be approximately four times that of the control.

\section{Discussion}

The islet culture system established in the present study is useful of analysing the function of islet cells of pregnant and non-pregnant rats. Insulin secretion from the islets was stimulated by glucose in a dose-dependent manner for concentrations in the physiological range. The secretory response of insulin to the glucose depends on the reproductive process. The response of pregnant rat islets to glucose was greater than

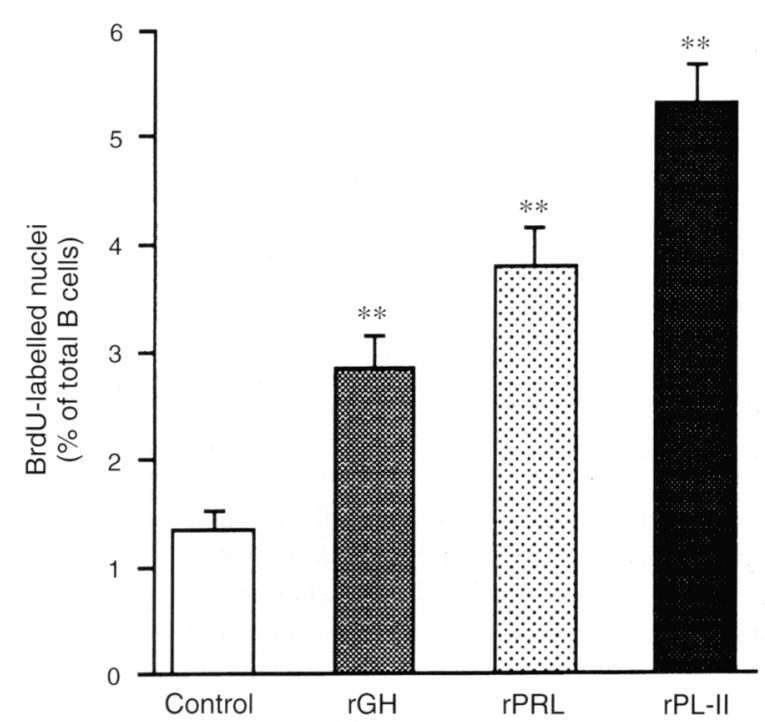

Fig. 6. Effects of rat placental lactogen-II (rPL-II), rat prolactin (rPRL) and rat growth hormone $(\mathrm{rGH})$ at $1000 \mathrm{ng} \mathrm{ml}^{-1}$ on incorporation of 5'-bromo-2'-deoxy-uridine (BrdU) into B-cell nuclei. The islets from non-pregnant rats were cultured with $10 \mathrm{mmol} \mathrm{BrdU} \mathrm{I}^{-1}$ for the last $24 \mathrm{~h}$ of culture. Data are shown as mean \pm SEM $(n=11$ or 12). $* * P<0.01$ compared with control.

that of non-pregnant rat islets and increased as pregnancy advanced. These results indicate that the glucose stimulation threshold in the islets is reduced and glucose-stimulated insulin secretion is enhanced as pregnancy advances. These functional changes in maternal islets are thought to be needed to accommodate the increased demand of insulin particularly during the last half of pregnancy.

rPL-I enhances islet function (Brelje et al., 1993), which indicates that rat placentae directly regulate insulin secretion during mid-pregnancy in rats. However, as rPL-I appeared in maternal circulation only during mid-pregnancy, the presence of other factor(s) that directly regulate insulin secretion is presumed during the last half of pregnancy. This was verified by adding the culture medium of rat trophoblasts obtained 
from the placentae of rats at day 13 of pregnancy to the islet culture system. This led to stimulation of insulin secretion from the islets in a dose-dependent manner. These resuits suggest that there is a factor(s) that directly regulates insulin secretion in the culture medium of trophoblasts. After mid-pregnancy, rPL-I disappears rapidly from the maternal circulation, and rPL-II is predominantly secreted during the rest of the period. Most of the cells cultured were trophoblast giant cells and polygonal cells obtained from the junctional and labyrinth zones of the chorioallantoic placenta (Kishi et al., 1992). Our previous study confirmed immunohistochemically that approximately $70 \%$ of the trophoblast cells are rPL-II positive cells. In addition, the average concentrations of rPL-II in trophoblastcultured medium are estimated to be more than $300 \mathrm{ng} \mathrm{ml}^{-1}$ by radioimmunoassy (data not shown). These findings suggest that rPL-II stimulates insulin secretion directly during the last half of pregnancy.

When purified rPL-II was added to the islet culture system, insulin secretion was stimulated in a dose-dependent manner. rPL-II activity was more than double those of rPRL and rGH at the concentration of $100 \mathrm{ng} \mathrm{ml}^{-1}$ in islets from pregnant rats. The PRL concentration in maternal circulation after mid-pregnancy is extremely low in rats except just before parturition (Tonkowicz and Voogt, 1983), and the GH concentration gradually increases from 50 to $300 \mathrm{ng} \mathrm{ml}^{-1}$ in late pregnancy (Kishi et al., 1991). However, the gestational profiles of $\mathrm{rPL}-\mathrm{II}$ are characterized by a sustained increase in maternal circulation during the last half of pregnancy with a maximum concentration of approximately $1000 \mathrm{ng} \mathrm{ml}^{-1}$ (Ogren and Talamantes, 1988; Kishi et al., 1991). Taking into account these three hormone profiles in maternal circulation and our findings, we conclude that rPL-II is a physiological hormone regulating rat islet function during the last half of pregnancy.

When the islets were cultured with $1000 \mathrm{ng} \mathrm{ml}^{-1} \mathrm{rPL}-\mathrm{II}$, rPRL or rGH for 8 days, islets from pregnant rats displayed a nearly twofold increase in insulin secretion compared with islets from non-pregnant rats. This indicates that the islet function is significantly enhanced during pregnancy. Marynissen et al. (1983) have shown that the B-cell mass increased by $53 \%$ on day 20 of gestation compared with non-pregnant rats. In addition to changes in the B-cell mass, there are functional changes, including a decreased threshold for glucose stimulation (Sorenson and Parsons, 1985), enhanced glucose-induced insulin secretion (Green and Taylor, 1972), and enhanced insulin synthesis (Bone and Taylor, 1976). These functional changes may be induced both in vivo and in vitro by the lactogenic hormones prolactin and placental lactogen (Sorenson and Parsons, 1985; Brejle and Sorenson, 1991; Parsons et al., 1992). In pregnant rats, insulin secretion from the maternal islets would increase to harmonize the above changes systemically during pregnancy. The enhanced insulin secretion and increase in B-cell proliferation were correlated with the onset of placental lactogen secretion in the rats (Sorenson and Parsons, 1985; Parsons et al., 1992). These findings suggest that the functional adaptation of $\mathrm{B}$ cells is advanced throughout pregnancy by rPRL, rPL-I and rPL-II which are secreted at specific times during each period. Thus, insulin secretion in rat islets would change to match increasing demands for glucose which is indispensable for fetal growth especially during the last half of pregnancy.
The presence of prolactin receptors was demonstrated in rat islet $B$ cells and an increase in expression of prolactin receptors was found in rat islets during pregnancy (Sorenson and Stout, 1995). In the adult mouse liver, MPL-I and mPL-II bind to the same receptor as mPRL (Harigaya et al., 1988), but mouse PLs do not bind to the GH receptors. In rats, one of the gestational hormones, luteotropin, secreted from the decidua binds specifically to rPRL receptors (Gibori et al., 1984). These studies suggest that rPLs use the rPRL receptors in rat tissues. Probably, PRL receptors in $B$ cells would be at least one of the sites to which rPL-II binds during the last half of pregnancy. Although Freemark et al. (1994) reported that there is no specific binding site for rPL-II in pregnant rat pancreas, our results suggest cooperativity of binding of rPL-II to unique PL receptors and PRL receptors in maternal B cells, since rPL-II activity was found to be more than double that of rPRL at the concentration of $100 \mathrm{ng} \mathrm{m}^{-1}$ in pregnant rat islets in the present study. The explanation for the observation that $\mathrm{rPL}-\mathrm{II}$ has more potent activity in islet functions than rPRL remains to be determined.

This study investigated the rate of proliferation of B cells using the thymidine analogue, $\mathrm{BrdU}$, which is incorporated into replicating DNA and detected immunohistochemically by a specific anti-BrdU monoclonal antibody. Although the incorporation of $\left[{ }^{3} \mathrm{H}\right]$ thymidine during the S-phase of the cell cycle has been widely used as an index of DNA synthesis and cell proliferation in islets (Logothetopoulos, 1972; Swenne et al., 1980), the islets comprise histologically multiple cell types including four types of endocrine cell and non-endocrine cells such as fibroblasts and endothelial cells (Bonner-Weir and Smith, 1994). The non-endocrine cells have been shown to have much higher thymidine incorporation (Devroede et al., 1990). These findings suggest that the incorporation of $\left[{ }^{3} \mathrm{H}\right]$ thymidine into islet cells do not accurately reflect B-cell proliferation. To resolve this problem, we developed a double immunofluorescent staining method to obtain more reliable data on the rate of proliferation of B cells in islets.

B-cell growth is expected to include three aspects: neogenesis of $B$ cells from precursors, changes in the size of individual B cells, and B-cell proliferation (Swenne, 1992). In the present study, it is not clear whether rPL-II affects neogenesis of $B$ cells from precursors and growth in the size of individual B cells. Recent work has suggested that lactogenic hormones induce islet neogenesis and increase islet size (Parsons et al, 1995). The effects of rPL-II on islet neogenesis and growth during pregnancy remain to be determined. Proliferation of existing islet cells occurs late in fetal development and has been thought to be the principal means by which islet mass increases after birth (Hellerstrom et al., 1988). There is a possibility that B-cell replication plays an important role in increasing B-cell mass during pregnancy. The present study suggests that the stimulatory effect of rPL-II on B-cell proliferation is at least one of the mechanisms by which B-cell mass is increased during pregnancy.

Like other stomatic cells, the B cell passes through a cell cycle that can be subdivided into several distinct phases (Hellerstrom et al., 1988). In general, cells must enter an active cycle for proliferation. Most cell populations of islet B cells have been considered to be in an irreversible $G_{0}$ phase, i.e. unable to re-enter the cell cycle (Teitelman et al., 1988). In adult 
rats, it has been estimated that the proliferative compartment (that is, the fraction of $\mathrm{B}$ cells capable of re-entering the cell cycle for $24 \mathrm{~h}$ ) is less than $3 \%$ compared with about $10 \%$ in the fetal rat (Swenne, 1983). In the present study, the proliferation rate of $\mathrm{B}$ cells in the presence of $1000 \mathrm{ng} \mathrm{rPL-II} \mathrm{ml}^{-1}$ for 8 days was $5.3 \%$. This value exceeded the estimated proliferative compartment value of adult rat $B$ cells, suggesting that rPL-II has the potential to increase the estimated proliferative compartment value of adult rat $\mathrm{B}$ cells. The proliferative compartment value can be increased by increasing the number of cells re-entering the cell cycle or shortening the duration of the cell cycle. Recently Brelje et al. (1994) suggested that rPRL stimulates quiescent $\mathrm{B}$ cells to re-enter the cell cycle and divide. This finding points to the possibility that rPL-II stimulates quiescent $B$ cells to re-enter the cell cycle as one of the mechanisms by which it increases the rate of proliferation of $\mathrm{B}$ cells during the last half of pregnancy. The effects of rPL-II on the duration of the B-cell cycle remain to be determined.

In the present study, we have demonstrated that rPL-II is a potent stimulator of insulin secretion and B-cell proliferation of islets. This finding is in agreement with the previous finding that mPL-II has the potential to stimulate insulin secretion and B-cell proliferation of mouse islets (Brelje et al., 1993). Moreover, the effects of rPL-II are greater than those of rPRL, which are much greater than those of $\mathrm{GH}$ in both insulin secretion and B-cell proliferation. Although PLs, PRL and GH may be regulators of islet function and growth (Nielsen, 1982; Nielsen et al., 1986), it is difficult to interpret these results because of differences in the use of homologous versus heterologous hormones in each study (Brelje et al., 1989). For example, human GH is known to have potency of both somatogenic and lactogenic activities when used with rat tissues (Nicoll et al., 1986). Similar issues may occur within rat PRL-GH families. To avoid these problems, we investigated the effects of IPL-II, rPRL and $\mathrm{rGH}$ on islet function in a homologous system and demonstrated that $\mathrm{rPL}-\mathrm{Il}$ is a potent stimulator in rat islet function during the last half of pregnancy. The present study also indicated that $\mathrm{rPRL}$ is more effective than $\mathrm{rGH}$ for increasing both insulin secretion and B-cell proliferation. These results are in agreement with those of previous studies (Sorenson and Parsons, 1985; Brelje and Sorenson, 1991; Parsons et al., 1992), which suggest that lactogenic hormones have more potent activity than somatogenic hormones in regulating rat islet function.

In conclusion, the present study demonstrates that rPL-II directly regulates insulin secretion and B-cell proliferation of maternal islets, indicating that rPL-II is one of the physiological hormones responsible for increasing islet function during the last half of pregnancy in rats.

The authors thank K. Tatemoto (University of Gunma, Maebashi) for his technical advice, Y. Hasegawa (New Drug Research Laboratories, Shionogi \& Co., Ltd) for his helpful advice and NIADDK for providing the pituitary hormones.

\section{References}

Bone AJ and Taylor KW (1976) Metabolic adaptation to pregnancy shown by increased biosynthesis of insulin in islets of Langerhans isolated from pregnant rats Nature 262 501-502
Bonner-Weirs and Smith FE (1994) Islet cell growth and the growth factors involved Trends in Endocrinology and Metabolism 5 60-64

Brelje TC and Sorenson RL (1991) Role of prolactin versus growth hormone on islet B-cell proliferation in vitro: implications for pregnancy Endocrinology $128 \quad 45-57$

Brelje TC, Allaire P, Hegre O and Sorenson RL (1989) Effect of prolactin versus growth hormone on islet function and the importance of using homologous mammosomatotrophic hormones Endocrinology 125 2392-2399

Brelje TC, Scharp DW, Lacy PE, Ogren L, Talamantes F, Robertson M, Friesen HG and Sorenson RL (1993) Effect of homologous placental lactogens, prolactins, and growth hormones on islet B-cell division and insulin secretion in rat, mouse, and human islets: implication for plancetal lactogen regulation of islet function during pregnancy Endocrinology 132 879-887

Brelje TC, Parsons JA and Sorensons RL (1994) Regulation of islet B-cell proliferation by prolactin in rat islets Diabetes 43 263-273

Devroede MA, Intveld PA and Pipeleers DG (1990) Deoxyribonucleic acid synthesis in cultured adult rat pancreatic B cells Endocrinology 127 1510-1516

Freemark M, Kirk K and Robertson M (1994) Cellular distribution of placental lactogen II binding sites in the pregnant rat Endocrine Journal 2 199-205

Gibori G, Kalison B, Basuray R, Rao MC and Hunzicker-Dunn M (1984) Endocrine role of decidual tissue: decidual luteotropin regulation of luteotropin in the maintenance of luteal steroidogenesis Endocrinology 15 1157-1163

Gotoh M, Maki T, Satomi S, Poter J, Bonner-Weir S, O'Hara CJ and Monaco AP (1987) Reproducible high yield of rat islets by stationary in vitro digestion following pancreatic ductual or portal venous collagenase injection Transplantation 43 725-730

Green IC and Taylor KW (1972) Effects of pregnancy in the rat on size and insulin secretory response of the islets of Langerhans Journal of Endocrinology 54 317-325

Harigaya T, Smith WC and Talamantes F (1988) Hepatic plancetal lactogen receptors during pregnancy in the mouse Endocrinology 122 2500-2511

Hellerstrom C, Swenne I and Andersson A (1988) Islet cell replication and diabetes. In The Pathology of the Endocrine Pancreas in Diabetes pp 141-170 Eds PJ Lefebvre and DG Pipeleers. Springer-Verlag, Heidelberg

Kishi K, Hirashiba M and Hasegawa Y (1991) Gestational profile of rat placental lactogen (rPL-II) and growth hormone (GH) in maternal and fetal serum, amniotic fluid and placental tissue Endocrine Journal 38 589-595

Kishi K, Hirashiba M and Hasegawa $Y$ (1992) Multiple forms of rat placental lactogen-II (rPL-II): purification and partial characterization of rPL-II Placenta $1363-79$

Kishi K, Itoh M, Kanamori S, Hirashiba M and Kawai M (1993) Stimulation of rat placental lactogen-II (rPL-II) secretion by cultured trophoblasts by insulin: development of a rat placental cell culture system and effects of peptide hormones on rPL-II secretion in vitro. Journal of Reproduction and Fertility 99 519-527

Logothetopoulos J (1972) Islet cell regeneration and neogenesis. In Handbook of Physiology pp 67-76 Eds DF Steiner and VA Freinkel. American Physiological Society, Washington DC

Marynissen G, Aerts L and Van Assche FA (1983) The endocrine pancreas during pregnancy and lactation in the rat Journal of Developmental Physiology 5 373-381

Metcalfe J, Stock MK and Barron DH (1994) Maternal physiology during gestation. In The Physiology of Reproduction pp 2145-2176 Eds E Knobil and JD Neill. Raven Press, New York

Nicoll CS, Mayer GL and Russel SM (1986) Structural features of prolactins and growth hormones that can be related to their biological properties Endocrine Review 7 169-203

Nielsen JH (1982) Effects of growth hormone, prolactin and placental lactogen on insulin content and release, and deoxyribonucleic acid synthesis in cultured pancreatic islets Endocrinology 110 600-606

Nielsen JH, Nielsen V, Pedersen LM and Deckert T (1986) Effects of pregnancy hormones on pancreatic islets in organ culture Acta Endocrinologica 11 336-341

Ogren L and Talamantes F (1988) Prolactin of pregnancy and their cellular source International Review of Cytology 112 1-65

Parsons JA, Brelje TC and Sorenson RL (1992) Adaptation of islets of Langerhans to pregnancy: increased islet cell proliferation and insulin secretion correlates with the onset of placental lactogen secretion Endocrinology 130 1459-1466 
Parsons JA, Bartke A and Sorenson RL (1995) Number and size of islets of Langerhans in pregnant, human growth hormone-expressing transgenic, and pituitary dwarf mice: effect of lactogenic hormones Endocrinology 136 2013-2021

Sorenson RL and Parsons JA (1985) Insulin secretion in mammosomatotropic tumor-bearing and pregnancy rats: a role of lactogens Diabetes 34 $337-341$

Sorenson RL and Stout LE (1995) Prolactin receptors and JAK2 in islets of Langerhans: an immunohistochemical analysis Endocrinology 136 4092-4098 Swenne I (1983) Effects of aging on the regenerative capacity of the pancreatic B-cell of the rat Diabetes 32 14-19
Swenne I (1992) Pancreatic beta-cell growth and diabetes mellitus Diabetologia Review 35 193-201

Swenne I, Bone AJ, Howell SL and Hellerstrom C (1980) Effects of glucose and amino acids on the biosynthesis of DNA and insulin in fetal rat islets maintained in tissue culture Diabetes 29 686-692

Teitelman G, Alpert S and Hanahan D (1988) Proliferation, senescence and neoplastic progression of cells in hyperplastic pancreatic islets Cell $\mathbf{5 2}$ 97-105

Tonkowicz PA and Voogt JL (1983) Termination of prolactin surges with development of placental lactogen secretion in the pregnant rat Endocrinology 133 1314-1318 